Journal of Teacher Education for Sustainability, vol. 23, no. 1, pp. 58-68, 2021

\title{
Making Change Visible - An Explorative Case Study of Dealing With Climate Change Deniers in Forest Education
}

\author{
Jens Hepper \\ Department of Education for Sustainable Development, \\ School Administration of Lower Saxony - Brunswick, Germany
}

\begin{abstract}
This case study addresses the issue of climate change denial among students in their first year of vocational education. It was possible to shake the belief that man-made climate change was not happening, through letting students measure the potential of natural forest vegetation and compare their findings with those gathered by their peers nine years earlier. The comparison revealed that old forests had turned into ecosystems, which were adapted for dryer warmer climates.

For education for sustainable development, forest education and biology lessons offer the opportunity to establish a long term project, in which peer-to-peer-learning over generations of students is possible, with a high rate of acceptance of the results generated by the former students.
\end{abstract}

Key words: education for sustainable development, forest education, forest pedagogics, peer learning, climate change education, climate change denial

\section{Introduction}

Climate change is one of the most prominent topics of our time. The activities of Greta Thunberg, Eco-Schools, etc., influence the daily lives of educators and students in many parts of the world (Nevett, 2019). While pupils often take action, a surprisingly high number of them voice a strong disbelief in the necessity to act and change their lifestyle. This goes so far that some teachers, who are very specific on this subject in their lessons, have been described using the derogatory term "warmist" (Freeman, 2017). Addressing the issue of climate change is Goal No. 13 of the 17 Sustainable Development Goals (SDGs) of the United Nations (United Nations eds., 2021). It is formulated as the necessity to "take urgent actions to combat climate change and its impacts"; these words show that taking actions against such ideas, concepts and beliefs is an important aspect of education for sustainable development (ESD).

Even though the subject of climate change education is of importance, it is one of those, which has been addressed to a lesser degree, compared to preschool, higher, and 
environmental education (Buttigieg \& Pace, 2013; Pipere et al., 2015). Due to this reason, the importance needs to be stressed (Andic \& Vorkapic, 2017).

Teachers of biology and geography are among the educators confronted most often with the subject of climate change, compared to those teaching other subjects. In case of German vocational education classes, this situation is even more dire. The students in such classes have had at least ten years of education on the subject of sustainable development, biology, etc. before pursuing their chosen career path. In this study, we explore the learning outcome of these ten years and how the students react to perceivable changes in a forest ecosystem, documented and described by themselves and former students nine years prior to them.

Following the macro-method of Forest Case Studies (Hepper, 2014; 2017), a learning approach based on peer-learning was chosen. Learning based on personal experience, as well as that of peers, is considered to have a comparatively high learning outcome (Hattie, 2013). Peer-to-peer education (Boyle et al., 2011) offers the advantage that the students receive their information from pupils with a similar background and set of values as their own. Therefore, "Peer learning, based on jointly generated evidence, is also an effective means to build capacity and foster scientific excellence. The body of knowledge it generates is a powerful tool for the development of evidence-based policy" (Guilmette, 2009, p. 11).

With learners of this age, identity formation and maintenance is an important and ongoing issue. One part of this, especially for students in vocational education and similar courses, is that teachers encourage students to think critically (Goldie, 2012). The relationship with parents and peers plays an important role in the formation of the identity (Kerpelman et al., 1997). Teachers, on the other hand, even when going to great lengths trying to influence identity formation regarding climate change, etc. in students, tend to only make a difference in 25-50\% of the students in their class (Kroger, 2004). This is quite low, as 50-75\% of a class still do not accept the necessity to act according to the standards communicated by the majority of the scientific community. This means that an approach should be chosen in which peer-learning is part of the process, as it was done in this study.

According to motivated reasoning, it can generally be assumed that few people are truly open-minded. This is especially true when their firmly held beliefs are challenged by disconfirming information (Strickland et al., 2011). The trouble is the emotional bias used to justify why a human being, in this case the students, should not behave in a way that would reduce the effect of climate change. Taking into account the years 2018 until 2020, many people were quite happy with the "good", sunny, dry weather a typical problem in the global warming and climate change discussion (Hahn et al., 2016; Druckmann \& McGrath, 2019; Luo \& Zhao, 2019). It is suggested that people need "evidence" on this subject to accept the information given. This can only be accomplished by sources considered credible (Druckmann \& McGrath, 2019). These credible sources can be peers and self-conducted research.

\section{Material and Methods}

The objective of this research is to identify an approach to dealing with climate change deniers among students in school-based education for sustainable development and to give teachers and educators a tool for addressing this issue in a way that circumvents the typical argumentation of climate change denial. 
The study was conducted in entry-level vocational education classes for agricultural professions in Germany. Forestry and forest-ecology is no subject of the curriculum at this point. This education culminates in level 4 qualification according to the European Qualifications Framework (EQF). Doing research in these kind of classes is interesting due to the fact, that they include students from various educational backgrounds. After four years of elementary schooling, German students normally visit a secondary school. In Germany, these are known as the Hauptschule, Realschule, and Gymnasium. The latter lays the foundation for academic education. For this type of education, a student needs good marks (B or better) in the relevant subjects of mathematics, German and Sachunterricht, a subject that is a combination of local history, geography and biology in elementary school. The least capable students attend the Hauptschule, which is regularly completed after five additional years, with the Realschule taking six years, and the Gymnasium eight years longer, respectively. Many vocations require students to have at least completed the Realschule. The agricultural professions normally have mixture of the various backgrounds: about $5 \%$ of the students enter having not passed any exam at all (these are offered after grade 9, 10 and 12/13 for the aforementioned Hauptschule, Realschule, and Gymnasium), $10 \%$ having fulfilled the general qualification for university entrance with a Gymnasium degree (Abitur). Further $30 \%$ of the students enter the education after grade 9 with a Hauptschule degree, with the remaining $55 \%$ come from the Realschule (Hepper, 2016).

Biology related research in German vocational education classes is very interesting due to the fact the general education is considered to be completed at this point of their lives. The subjects taught in vocational education are the German and English language, politics, physical training, computer science and religious education. During the United Nations Decade of Education for Sustainable Development, the idea arose to integrate a "sustainability curriculum" by identifying potential approaches and integrating forestry related climate change education in the curriculum.

Forestry and forest ecosystems have a long standing history and tradition in German education (Hepper, 2017), so this can be considered to be a very well and thoroughly covered subject, which offers the best approach to sustainability education. In LowerSaxony, forest ecosystems are an integral part of the Abitur (A-Level examinations at the Gymnasium) as well as elementary and other secondary education. The students learn over the years how to differentiate between pristine, near-natural and economically managed forests and how to identify the autochthonous tree and plant species, a task which is often combined with gathering plants for a herbarium. The comparatively high importance of forest ecosystems in the German education system is linked to the historical and cultural significance of forests in Germany, following the $19^{\text {th }}$ century focus on this part of nature in literature and art (Wilson, 2012). Due to this reason, it can generally be assumed that students are well aware of the relevance of the forest ecosystem - its needs, growth, and development over time - as well as the comparatively slow changes happening there.

In recent years, these changes have been accelerated by climate change (Chaplin et al., 2000; Sanz-Elorza et al., 2003; Walther et al., 2002; Parmesan \& Yohe, 2003). Thus, forests appear to be the ideal ecosystems for monitoring climate change with students.

In 2011 and 2020, two bodies of students were asked to explore a piece of grassland situated between a forest and river, and the forest next to it, and to determine the natural forest ecosystem. The active learning situation for both groups was as follows: 
"The local authorities plan to replant a forest in this area. You are tasked, to determine the potential natural forest-ecosystem!" The determination process was done in groups of three, with one group of four students. Each group had to conduct several circular sample areas of $10 \mathrm{~m}^{2}$ each. The first was set in the immediate vicinity of the river, with the closest edge of the circle being $2 \mathrm{~m}$ from the river bank. Three more sample areas were in the grassland, one at the edge of the forest and three more in forest itself. In total, 112 circles were measured in 2011 and 120 circles - in 2020. Regarding the size of the area (approximately $6.5 \mathrm{ha}$ ), 40 circles were deemed sufficient, from the forest science perspective, to determine the natural forest ecosystem (Kramer \& Akça, 1995; Gadow \& Meskauskas, 1997).

The same was done in 2012 and 2020. Here a beech forest was the focus habitat. The active learning situation was: "Determine wether or not, this area is a near-natural forest!" The determination process was done in the aforementioned pattern, starting $2 \mathrm{~m}$ from a forest service road, with a total of 126 samples in both years.

The plants found were floristically identified and sorted by their plant communities, according to the standards of forest sciences (Schmidt \& Dohrenbusch, 2003). In regards to climate change, which is - as a phenomenon - better perceivable over a long time (Tan et al., 2018), educators face the problem that the students' time spent in school is comparatively short. To mitigate this problem, an approach was chosen in which several generations of students could "interact" with each other over a long period of time by conserving the results of past studies in a "forest logbook".

The students in each of the studied classes were between 17 und 54 years of age (with a median age of 20 years in each group). There were 42 students in 2011 and 46 students in 2020 as well as 28 students in 2012 and 2021. The older students began pursuing vocational education after serving in the military for a lengthy time.

A qualitative approach was chosen due to the small number of students. The case study, as a research method, has been applied in educational research for a very long time (MacDonald \&Walker, 2006). It is often utilized in situations in which new educational approaches have to be evaluated. More experimental methods often cannot answer the questions voiced by the teachers participating in such projects regarding how to incorporate the results of educational research in the school-based curriculum (MacDonald \& Walker, 2006, p. 11). In this regard, the case study can be considered an "instance in action" (MacDonald \& Walker, 2006, p. 12), where various scientific approaches are combined (MacDonald \& Walker, 2006, pp. 12-13), to form a longlasting "picture" of the case observed, to conserve the results and experiences generated.

For all classes, group interviews were held, examining the opinion of the students on the subject of climate change. Group interviews, instead of individual interviews, were used due to the focus on peer learning and to identify the consensus in the peer group (Frey \& Fontana, 1991). For this purpose, each class was divided in teams of three (if necessary four) students. Each team was given a set of four questions to be answered in their group. During the group discussion, an agreement on this subject had to be found in the classes.

The items covered included:

- Discuss the issue of man-made climate change!

- Discuss the issue of man-made loss of biodiversity!

- Describe actions necessary for sustainable land use!

- Describe actions necessary for sustainable consumption! 
With the 2020 and 2021 groups, interviews were held in the forest as well. Here the students were asked to find an explanation for their findings on the changes in the ecosystems.

During the first and second set of interviews, the behavior of the students was studied. Typically when feeling discomfort, the subject's movement accelerates and their movements use more space (Carneiro et al., 2012). All of the interviews were recorded.

\section{Results}

Only two of the 15 groups in 2020 and one of the 9 groups in 2021 complied with the scientifically established perspectives on climate change being a man-made problem. The majority considered climate change to be overrated ( $n=9 / 15$ and $7 / 9$ ), stating that humanity certainly faced ecological problems, most of which originated from nonsustainable consumer behavior, while asserting that climate change was not a manmade issue. These claimed that the weather extremes of the last years, such as droughts, etc. were solely caused by short-lived weather phenomena. The remaining groups outright denied any effect ( $n=4 / 15$ and $1 / 9$ ), even going so far as questioning the existence of climate change at all. This was interesting to note due to the fact that the 2011 and 2012 groups, having for the most part grown up in the 1990s and 2000s, universally agreed that climate change was occurring and perceived this as a problem. Man-made loss of biodiversity, as well as the actions necessary for sustainable land use and consumption showed only minor differences, with the 2011 and 2012 classes generally assuming an "I need to change" perspective, while the 2020 groups saw the necessity of others changing.

All groups showed a calm behavior in the discussion, apparently being very secure about their opinions.

During the first year of the ecosystem monitoring with students in 2011, the groups found a riparian forest ecosystem in the area. Alnus glutinosa, Populus nigra and Salix spec. formed the tree layer of the forest, and were prevalent in the shrub and herb layer as well. Accordingly, the students decided that they would plant a Stellario-nemorumAlnetum-glutinosae (Hofmeister, 2004, p. 186), a forest adapted to annual flooding and close proximity to the groundwater.

As for the second excursion in 2020, the students found that the aforementioned forest had turned into the drier Aceri-Tilietum (Hofmeister, 2004, p. 155), with the tree species mentioned above still forming the tree layer, but with Acer platanoides, Acer pseudoplatanus, Ulmus laevis, Tilia platyphyllos, Tilia cordata visibly replacing the Alnus and Populus in the shrub and and especially herb layer, as well as other indicator plants for wet soil.

The average wetness of the soil was 7.6 in 2011 and 5.2 in 2020, representing the mean of all the plants registered. The scale goes from $0=$ very dry to $10=$ extremely wet soil. The Aceri-Tilietum is considered to be adapted to a more dry soil, with high and cold humidity (Hofmeister, 2004, p. 155), typical of this area. Most likely the draughts during the years 2018, 2019 and early 2020 led to this situation, which helped the mentioned forest-ecosystem thrive.

Most of the students ( $n=39 / 45$ ) of the 2020 group had expected to find an Alnetum there, due to the close vicinity to the river. These quickly voiced their surprise on the findings during the group interviews. 
After being given the results of the 2011 groups, the 2020 students were asked for possible reasons explaining this change, as the results gathered earlier conformed their expectations.

All of the 2020 groups came to the conclusion "climate change" - even those, who had voiced a strong disbelief regarding climate change and its impact on ecosystems. A new level of concernment became obvious, particularly in those who had the strongest opposition before. Their body language and behavior showed signs of discomfort, compared to their rather laid back outward appearance during the first interview. Their movements became faster, with their gestures taking more room. Sudden, rapid movements of the body, etc. were typical. Apparently, they had had the opportunity to experience a direct effect of climate change for the first time, not with some data given out by climatologists, but after looking at an area by themselves and using the data gathered by peers just a few years ago.

During the second year of the ecosystem monitoring with students in 2012, the groups found a Carici-fagetum (Hofmeister, 2004, p. 161). Fagus silvatica, Quercus petraea, and Acer campestre formed the tree layer, forming the shrub and herb layer as well. In 2021, the students found plants typical of Fraxinus ornus-Ostrya carpinifoliacommunities (Dakskobler, 2015), with a similar change in the average wetness of the soil, with 6.1 in 2012 and 4.2 in 2021, representing the mean of all the plants registered.

The plants found, like Berberis vulgaris, Euphorbia carniolica, Brachypodium rupestre, etc. pointed out to this plant community, which is normally found in climates considered to be much warmer, with the 2012 results meeting the expectations.

Especially with the very obvious damages to the old beeches in the forest, with many dead branches, etc. the conclusion of climate change being the reason for these changes, was easily found. The body language with the 2021 group showed signs of shock and astonishment, with open mouths and eyes wide open. The students voiced, that they had not considered the situation to be as dire as it was found.

Due to the students coming to these solutions very fast, they were encouraged to find other explanations, such as more light coming to the ground due to cut-down trees, etc. As this was not the case in either nature reserve, with the exception of one tree felled by a beaver in 2020, other explanations for this change had to be found. As with the situation of no shift in the tree species forming the tree layer, and these being comparatively old, again the students agreed upon climate change as being the sole reason for the situation found.

\section{Discussion}

Existing approaches to addressing the issue of climate change include role plays (Rumore et al., 2016), furthering critical thinking (Anderson, 2010), engaging in discussions, interviewing scientists, addressing misconceptions, and engaging projects in schools and communities (Monroe et al., 2019). The most effective methodological approaches include the engaging of learners in environmental education and education for sustainable development programs (Monroe et al., 2019). Most of these studies look into educating children in primary and early secondary education, without regard of climate change denial, which tends to develop during adulthood (McCright \& Dunlap, 2011; Krange et al., 2018). As education for sustainable development is considered to 
be a concept for life-long learning, the educational approach offered in this study, could be a way of furthering this concept.

The difference between those students having grown up in the 1990s, compared with those who grew up in the 2000s, was to be expected. In this case study, we found a difference in the belief of whether climate change was actually happening between Generation Y (birth years 1980-1995) and Generation Z (1996-2010) (Anderson, 2004; Eisner, 2005; Dyson \& Zink, 2007; Eckleberry-Hunt \& Tucciarone, 2011; Seemiller \& Grace, 2016; Patel, 2017).

Generation $\mathrm{Y}$ is considered to be heavily influenced by the 9/11-terrorist attacks on the World Trade Center and other real or perceived threats (Eisner, 2005; Dyson \& Zink, 2007; Eckleberry-Hunt \& Tucciarone, 2011). In previous studies, they have been characterized as being more inclined to the subjects addressed by education for sustainable development and trying to make a better world for their own children (Howe, 2016; Hepper, 2019).

Generation Z, on the other hand, is considered to be in need of a wake-up call to participate (Anderson, 2004). Generally speaking, they are more optimistic regarding their future, which may have contributed to the differing perspectives on the direness of climate change (Seemiller \& Grace, 2016). In this study, the changes in the forest ecosystem apparently served as a sufficient wake-up call for the students to change their mind.

The peer-to-peer-learning approach chosen was the core principle to deal with climate change deniers in education. Using data gathered by their peers nearly a decade earlier, some of them even known personally to the current students, made a discernible impact on their views toward climate change. Even when being pushed by the teacher to find another explanation, none of the students offered an alternative. Thus, forest ecosystems and forest related education can be considered to be a major approach in climate change education.

The species of the tree layer, the river and even the light influencing plant growth had all remained the same, which could be considered crucial at this point. Would there have been major changes, for example due to a natural disaster or the harvesting of timber, another solution would have been possible, potentially resulting in disbelief. Older forest nature reserves, with a fully grown stock of trees, are particularly suitable for witnessing such changes. Furthermore, forest ecosystems that are already well adapted to drought are also not suitable due to the fact that many of the plants there will be more resistant to the climatic changes we can measure with students. In these cases, where one nature reserve even had been named "riparian forest" nearly 50 years ago, the name served as another simple fact that could not be disproved, adding to the gravity of the visible alterations in this ecosystem as a proof for climate change. Therefore, these types of forest appear to be more suited for educational purposes in regard of climate change.

The fact that all student groups in 2020 and 2021, independently of each other, came to the same conclusion furthered the acceptance of the idea of man-made climate change.

In many countries, forests and forest ecosystems are part of the school curriculum for students of various age. Adapting the scientific approach of identifying the potential natural vegetation for students is a comparably simple task. In most classes, this is just a momentary exploration without a lasting effect, solely executed for the teacher asking 
for it. Without the peers, without reading their names on the old sheets of paper, without knowing them, it might have been a much more difficult task to convince the students of the effect of climate change on the forest ecosystem.

For educators, one approach could be to establish an archive on the results of such tasks, with the annual results being gathered and published, like the "forest logbook" mentioned above. This could be done as part of a project, like an "earth week", etc. On the other hand, forest services and forest education institutions could offer the necessary infrastructure through forest laboratories.

\section{Conclusion}

Climate change is one of the most prevalent and pressing topics of our time and one of the 17 Sustainable Development Goals of the United Nations, giving credence to the importance of addressing this issue in any educational context. Even though the interdependencies between consumer behavior, carbon-dioxide cycles, etc. are widely known and accepted, a growing number of the population deny the existence of these issues. To address this issue in school-based education for sustainable development, the monitoring of plant ecosystems in nature reserves can be a way to reduce the perception that climate change is not an issue. Therefore, keeping a "forest logbook" where each generation of students can enter their findings is an integral part. The "forest logbook" methodology should be tested as a "nature logbook" for other ecosystems and fragile plant societies as well, but most likely the potential damage done to dry grassland, etc. could be too high. For educating students, as part of education for sustainable development, the approach should be used to introduce long-lasting forest-related projects and conserve the results of the different classes over time. This can give the students and teachers a purpose and help further the development of helpful behavior in conserving biodiversity.

\section{References}

Anderson, A. (2010). Combating climate change through quality education. Global Economy and Development, Policy Brief 2010-03, The Brookings Institution.

Anderson, J. (2004). Educating Generation Zzz... . Phi Kappa Phi Forum, Bd. 84, Ausg., 4, 59-60.

Andic, D., \& Vorkapic, S. T. (2017). Teacher education for sustainability: The awareness and responsibility for sustainability problems. Journal of Teacher Education for Sustainability, 19(2), 121-137.

Boyle, J., Mattern, C. O., Lassiter, J. W., \& Ritzler, M. S. (2011). Peer 2 peer: Efficacy of a course-based peer education intervention to increase physical activity among college students. Journal of American College Health, 59(6), 519-529. doi: 10.1080/ 07448481.2010.523854

Buttigieg, K., \& Pace, P. (2013). Positive youth action towards climate change. Journal of Teacher Education for Sustainability, 15(1), 15-47.

Carneiro, D., Castillo, J. C., Novais, P., Fernández-Caballero, A., \& Neves, J. (2012). Multimodal behavioral analysis for non-invasive stress detection. Expert Systems With Applications, 39, 13376-13389. 
Chapin, F., Zavaleta, E., Eviner, V., Naylor, R. L., Vitousek, P. M., Reynolds, H., Hooper, D. U., Lavorel, S., Sala, O. E., Hobbie, S. E., Mack, M. C., \& Díaz, S. (2002). Consequences of changing biodiversity. Nature, 405, 234-242. https://doi.org/10.1038/35012241

Dakskobler, I. (2015). Phytosociological description of Ostrya Carpinifolia and Fraxinus Ornus communities in the Julian Alps and in the Northern part of the Dinaric Alps (NW and W Slovenia, NE Italy). Hacquetia, 14(2). doi: 10.1515/hacq-2015-0001

Druckmann, J. N., \& McGrath, M. C. (2019). The evidence for motivated reasoning in climate change preference formation. Review Article in Nature Vlimate Cange. https://faculty.wcas.northwestern.edu/ jnd260/pub/Druckman \% 20and \% 20McGrath.pdf

Dyson, M., \& Zink, R. (2007). Educating Generation Y in alternate settings: What seems to work. Full paper for presentation at the Annual Conference of AARE, Freemantle.

Eckleberry-Hunt, J., \& Tucciarone, J. (2011). The challenges and opportunities of teaching "Generation Y”. Journal of Graduate Medical Education, 458-461.

Eisner, S. P. (2005). Manageing Generation Y. S. A. M. Advanced Management Journal, 70(4), 4-15.

Freeman, B. (2017). When climate change denial shows up in the classroom. What to do when you're labeled a warmist. https:/www.weareteachers.com/climate-changedenial/

Frey, J. H., \& Fontana, A. (1991). The group interview in social research. The Social Science Journal, 28(2), 175-187. https://doi.org/10.1016/0362-3319(91)90003-M

Gadow, K. V., \& Meskauskas, E. (1997). Stichprobenverfahren zur Erfassung von Naturverjüngung [Sampling young trees). AFZ / Der Wald, 52(5), 247-248.

Goldie, J. (2012). The formation of professional identity in medical students: Considerations for educators. Medical Teacher, 34(9), e641-e648. doi: 10.3109/0142159X. 2012.687476

Guilmette, J.-H. (2009). Power of peer learning: Networks and development cooperation. IDRC. hdl: 10625/28624.

Hahn, U., Harris, A. J. L., \& Corner, A. (2016). Public reception of climate science: Coherence, reliability, and independence. Topics in Cognitive Science, 1, 180-95. doi: 10.1111/tops.12173

Hattie, J. A. C. (2013). Lernen sichtbar machen [Visible learning]. Schneider Publishers, Hohengehren.

Hepper, J. (2016). Agrarische Lehrerbildung. Berichte über Landwirtschaft, Zeitschrift für Agrarpolitik und Landwirtschaft des Bundesministeriums für Ernährung, Landwirtschaft und Verbraucherschutz, Band 94, Heft 3.

Hepper, J. (2017). Geschichtliche Betrachtung der agrarischen Unterrichtsmethodik. Landbauforschung. Applied Agricultural and Forestry Research, 67(3-4), 111121.

Hepper, J. (2019). The influence of generation and experiencing daily routines on educators' training. Journal of Teacher Education for Sustainability, 20, doi: 10.2478/jtes-2018-0017

Hofmeister, H. (2004). Lebensraum Wald [Eco-system forest]. Kessel publishers. 
Howlze, N. (2016). Meet Mr. and Mrs. Gen X: A new parent generation. Strategies for school leaders when dealing with customer-service expectations, self-interest and stealth-fighter tactics. http://www.aasa.org/SchoolAdministratorArticle.aspx? $\mathrm{id}=1112$

Kerpelman, J. L., Pittmann, J. F., \& Lamke, L. K. (1997). Toward a microprocess perspective on adolescent identity development: An identity control theory approach. https://doi.org/10.1177/0743554897123002

Kramer, H., \& Akça, A. (1995). Leitfaden zur Waldmeßlehre [Measuring forests a guide]. J. D. Sauerländer's Publisher.

Krange, O., Kaltenborn, B. P., \& Hultman, M. (2018). Cool dudes in Norway: Climate change denial among conservative Norwegian men. Environmental Sociology. https://doi.org/10.1080/23251042.2018.1488516

Kroger, J. (2004). Identity in adolescence. Routledge.

Luo, Y., \& Zhao, J. (2019). Motivated attention in climate change perception and action. Frontiers in Psychology, 10, 1541. doi: 10.3389/fpsyg.2019.01541

MacDonald, B., \& Walker, R. (2006). Case study and the social philosophy of educational research. Cambridge Journal of Education, 5(1), 2-11. doi: 10.1080/ 0305764750050101

McCright, A. M., \& Dunlap, R. E. (2011). Cool dudes: The denial of climate change among conservative white males in the United States. Global Environmental Change, 21, 1163-1172.

Monroe, M. C., Plate, R. R., Oxarart, A., Bowers, A., \& Chaves, W. A. (2019). Identifying effective climate change education strategies: A systematic review of the research. Environmental Education Research, 25(6), 791-812.

Nevett, J. (2019). The Greta effect? Meet the schoolgirl climate warriors. BBC News. Archived from the original on 22 July 2019.

Parmesan, C., \& Yohe, G. (2003). A globally coherent fingerprint of climate change impacts across natural systems. Nature, 421, 37-42. https://doi.org/10.1038/nature 01286

Patel, D. (2017). How to influence Generation Z through education. https://www.forbes. com/sites/deeppatel/2017/11/30/how-to-influence-generation-z-through-education/ \#4644970bee50

Pipere, A., Veisson, M., \& Salite, I. (2015). Developing research in teacher education for sustainability: UN DESD via the Journal of Teacher Education for Sustainability. Journal of Teacher Education for Sustainability, 17(2), 5-43.

Rumore, D., Schenk, T., \& Susskind, L. (2016). Role-play simulations for climate change adaptation education and engagement. https://dc.law.utah.edu/cgi/viewcontent.cgi? article $=1029 \&$ context $=$ scholarship

Schmidt, W., \& Dohrenbusch, A. (2003). Skript zum Modul Waldbauübungen. Selfpublished, Göttingen.

Seemiller, C., \& Grace, M. (2016). Generation Z goes to college. John Wiley \& Sons.

Strickland, A. A., Taber, C. S., \& Lodge, M. (2011). Motivated reasoning and public opinion. Journal of Health Politics, Policy and Law, 36(6), 935-944. doi: 10.1215/ 03616878-1460524

Tan, X., Gan, T. Y., \& Horton, D. E. (2018). Projected timing of perceivable changes in climate extremes for terrestrial and marine ecosystems. Global Change Biology. https://doi.org/10.1111/gcb.14329 
United Nations eds. (2021). SDG knowledge. https://sdgs.un.org/goals/goal13, 08.05.2021

Walther, GR., Post, E., Convey, Menzel, A., Parmesan, C., Beebee, T. J. C., Fromentin, J.-M., Hoegh-Guldberg, O., \& Bairlein, F. (2002). Ecological responses to recent climate change. Nature, 416, 389-395. https://doi.org/10.1038/416389a

Wilson, J. K. (2012). The german forest: Nature, identity, and the contestation of a national symbol, 1871-1914. University of Toronto Press.

Correspondence concerning this article should be addressed to Jens Hepper, Upper Councillor in Education, Department of Education for Sustainable Development, School Administration of Lower Saxony - Brunswick, Düderoder Straße 38, 37589 Kalefeld, Germany. Email: jens.hepper@rlsb.de 